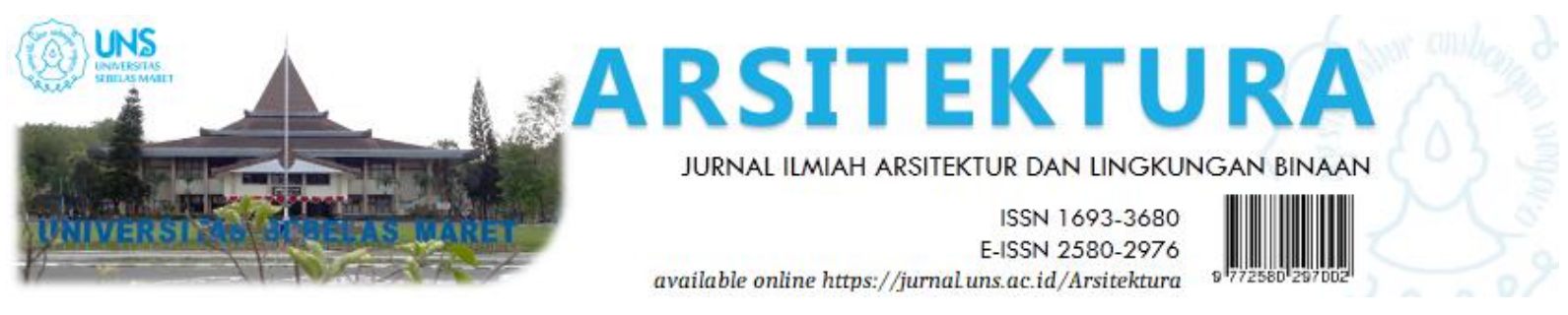

Volume 19 Issue 1 April 2021, pages:75-84

\title{
Model Perancangan Pusat Komunitas Kampung Keparakan sebagai Antitesis Panti Asuhan: Fasilitas Reunifikasi Keluarga
}

\section{Design Model of Keparakan Kampong Community Center as Orphanage Antithesis: Family Reunification Facility}

\author{
Gilang Dwi Alridho ${ }^{1 *}$, Kurnia Widiastuti ${ }^{2}$ \\ Departemen Teknik Arsitektur dan Perencanaan, Fakultas Teknik Universitas Gadjah Mada ${ }^{1 *}$ \\ gilang.dwi.a @ mail.ugm.ac.id \\ Departemen Teknik Arsitektur dan Perencanaan, Fa kultas Teknik Universitas Gadjah Mada²
}

DOI: https://doi.org/10.20961/arst.v19i1.45549

Received: November 12,2020 Revised: March 13,2021 Accepted: March 16,2021 Available online: April 30,2021

\begin{abstract}
Child institutionalization (orphanage) is considered as a crime due to child segregation from their family to a residential care institution. In Indonesia, about $94 \%$ of 500.000 children are still having at least one biological parent and they live in orphanages. There are several badimpacts in orphan mental health such as less confidence, indifferent, reserved, and suffering dramatic developmental delays. Therefore, there is a need to develop the design of a facility to reunite the orphans and their family as an act of deinstitutionalization. This facility context is integrated to and managed by (kampong) community center as a way to decentral and deinstitutionalize orphanages, whichneed the role of community as a mediator for orphans to reunite with their community and family. Since this article writes the research part as well as proposing a solution of design, inductive-abductivedeductive methods are used. According to data gathered and analyzed, main design problems formulated are how to design spaces (design ofopen space, counseling room, and integrat ion to other facilities) that encourage family reunification. Therapeutic Courtyard is the design concept synthesized based on those problems. First strategy is to create a playground theme to a central courtyard as a tool to encourage family interaction. Second is a counseling room as space that provides a sense of relief. Third solution is putting natural elements as a space enclosure as well as creating therapeutic effects.
\end{abstract}

Keywords: orphanage, children, community center, reunification

\section{PENDAHULUAN}

Di Indonesia, ada sebanyak $94 \%$ dari 500.000 anak masih memiliki minimal satu orang tua namun tinggal di panti asuhan (Lumos, 2014). Hal ini terjadi karena institusionalisasi anak, yaitu upaya memasukkan anak ke dalam sebuah pengasuhan institusional (seperti panti asuhan, di mana anak diinapkan dalam satu fasilitas hunian yang dikelola oleh suatu institusi atau yayasan).

Panti asuhan merupakan "rumah, tempat, memelihara dan merawat anak yatim atau yatim piatu" (KBBI, 2016b). Jika dilihat dari definisinya, fasilitas ini berperan sebagai solusi atas hilangnya hak anak berupa pengasuhan. Namun pada kenyataannya, banyak dari panti 
asuhan ini yang tidak berizin dan tidak terawasi dengan baik sehingga membahayakan anak yang ada di dalamnya. Panti asuhan juga memiliki karakteristik yang cenderung tertutup dan terpisah dengan komunitas, yang mana ini akan berefek signifikan pada tumbuh kembang anak. Anak menjadi tertutup, kurang percaya diri, tidak mampu memiliki kemampuan sosial yang baik (Eurochild, 2014). Tidak hanya itu, lebih dari 60 tahun penelitian internasional menunjukkan bahwa, tumbuh kembang anak di panti asuhan, memperlihatkan adanya perlambatan IQ (terpaut hingga 20 poin IQ dibanding anak yang tinggal di rumah), hal ini terjadi bahkan pada panti asuhan terbaik sekalipun (van IJzendoorn et al., 2008). Selain itu dalam konteks pengasuhan yang kurang baik, anak dapat terdampak berbagai gangguan emosi dan psikologi. Dampak yang paling terlihat adalah pertumbuhan fisik yang lemah karena kekurangan nutrisi dan adanya kerentanan penularan penyakit di dalam panti asuhan. (Moyo et al., 2015).

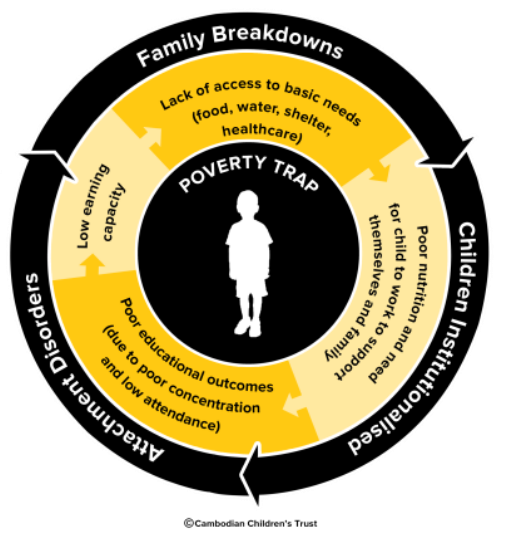

Gambar 1. Siklus perangkapkemiskinan Sumber:ipsify.com (Graham, 2017)

Gambar di atas menunjukkan kerentanan anak yang berada di panti asuhan dengan segala dampak negatifnya cenderung akan memiliki masa depan yang rentan dan terjebak dalam lingkaran kemiskinan.

Karena bahaya dan dampak yang berkepanjangan tersebut, maka muncullah satu gerakan yang disebut dengan deinstitusionalisasi anak. Deinstitusionalisasi anak (keterbalikan dari institusionalisasi anak) adalah suatu proses dalam sebuah negara yang mengarah pada pembentukan ulang sistem pengasuhan alternatif (Eurochild, 2014). Ada tiga tujuan dari deinstitusionalisasi anak yaitu:

1. Menguatkan pengasuhan berbasis keluarga dan inisiasi pengasuhan berbasis komunitas untuk mengurangi ketergantungan kepada institusi dan pengasuhan dengan sistem hunian. (alternatif)

2. Menyediakan layanan yang mendukung anak, keluarga dan komunitas untuk mencegah terjadinya pemisahan anak dengan orang tua. (dukungan)

3. Mempersiapkan proses anak meninggalkan panti asuhan dengan memberikan inklusi sosial yang baik untuk anak dan memfasilitasi proses transisi menuju kehidupan mandiri. (purna asuh).

Dari poin-poin di atas, tujuan dari tulisan ini adalah untuk memperoleh garis awal bentukan atau konsep fasilitas penyatuan kembali 'anak yatim' dengan keluarga dan ataupun komunitas yang merujuk pada tujuan deinstitusionalisasi anak poin ketiga yaitu pengembalian purna asuh, sehingga anak yatim dapat berkembang sebagai individu yang cakap ketika kembali kepada keluarga biologisnya maupun komunitas.

Untuk memperkuat gagasan deinstitusionalisasi, diperlukan skenario pengelolaan yang dekat dengan struktur sosial masyarakat. Dengan demikian, desain ini memilih skenario lokasi pada pusat komunitas kampung sebagai mediator program reunifikasi anak yatim kepada keluarga dan komunitas sesuai konteks budaya setempat.

\section{METODE}

Penelitian desain ini meliputi proses induktif, abduktif dan deduktif. Kajian induktif dilakukan dengan melakukan pendalaman literatur dan lapangan terkait dengan isu fungsi panti asuhan dan isu terkini terkait program sejenis. Kajian literatur mengumpulkan sumber pustaka cetak maupun dijital. Bentuk pustaka yang dicari berupa buku, jurnal maupun artikel berita dalam dan luar negeri. Kajian lapangan dilakukan untuk memahami dan mendalami permasalahan panti asuhan konvensional. Kajian ini dilakukan dengan observasi Panti 
Asuhan Yatim Putra Muhammadiyah Lowanu Yogyakarta serta wawancara terhadap pengelolanya. Dalam proses ini dirumuskan permasalahan anak yatim terhadap fungsi panti asuhan. Hal ini mendorong skema pengasuhan anak yang lebih efektif berupa fungsi fasilitas reunifikasi yang lebih bersifat menyatukan keluarga, bukan memisahkan seperti panti asuhan). Rekomendasi tersebut di atas kemudian digunakan sebagai dasar untuk memilih asumsi lokasi yang sesuai untuk model desain. Daerah Kampung Keparakan, Mergangsan Yogyakarta dipilih karena fasilitas reunifikasi membutuhkan organisasi dan lingkungan sosial yang relatif kuat seperti kampung. Konteks kampung juga khas sehingga modelnya mudah digeneralisasi dengan mudah untuk lokasi lain.

Data yang diperoleh dari proses di atas kemudian diseleksi, disusun dan dianalisis menjadi kumpulan pernyataan dan kata kunci masalah-masalah fungsi, teori, dan konteks. Proses analisis tersebut menghasilkan diagram masalah termasuk pernyataan masalah utama perancangan. Sesuai kekhasan penelitian desain, proses analisis ini dilanjutkan dengan sintesis konsep serta dilengkapi pernyataan transformasi konsep sebagai jawaban terhadap pernyataan masalah (abduktif). Hasil akhir dilengkapi pula ilustrasi transformasi desain yang merupakan penerjemahan transformasi konsep (deduktif).

\section{HASIL DAN PEMBAHASAN}

Anak-anak yang keluar dari panti asuhan memiliki keterbatasan yang perlu ditunjang agar dapat kembali, berperan dan bersosial dengan baik dengan lingkungannya. Anak-anak ini juga tidak memiliki tempat kembali ketika di suatu jalan kehidupan mereka mengalami kegagalan dan butuh akan dukungan moral dan material. Beberapa anak yang masih kecil butuh peran serta orang tua yang tidak akan bisa diganti keberadaannya dengan pengasuh, juga akan berdampak buruk kepada perkembangan mentalnya. Fasilitas yang dapat mendukung keberadaan mereka dan melengkapi tugas/peran dari panti asuhan digagas dalam pengembangan community center/pusat komunitas yang nantinya bersifat lebih terbuka, dikelola dan didukung oleh masyarakat setempat.
Community yang berarti komunitas adalah sekelompok orang dalam satu daerah yang saling berinteraksi antara satu sama lain (KBBI, 2016a). Sedang center yang berarti pusat, adalah sesuatu yang menjadi tempat kumpulan atau pokok bermacam hal atau kegiatan (KBBI, 2016c).

Selanjutnya adalah model pengembangan, yang dapat berarti satu bentuk desain yang ditingkatkan fungsi atau performanya lewat penyesuaian elemen komponennya agar lebih sesuai dengan tujuan model itu sendiri (Wicahyo, 2018).

Jika dirumuskan, maka Community basedservice (Layanan Berbasis Masyarakat) adalah sebuah sistem layanan yang membangun anak, keluarga, serta komunitas di tempat keluarga tersebut menetap (Child Welfare Information Gateway, 2017). Dukungan komunitas ini secara tidak langsung memperkuat komunitas itu sendiri. Selanjutnya, reunifikasi anak adalah kegiatan untuk menghubungkan kembali anak asuh dengan orang tua atau keluarganya melalui proses yang terencana dan terdukung oleh berbagai layanan (Apsari \& Nurwati, 2017). Jadi Community-Based Reunification Service Facility adalah sebuah sistem layanan berbasis masyarakat menyediakan layanan reunifikasi anak, keluarga, dan komunitas tempat mereka tinggal. Tempat ini nantinya juga akan didukung dengan fasilitas dan wadah-wadah lain yang ada di eksisting komunitas. Sistem inilah yang nantinya akan dikembangkan/ diaplikasikan pada pusat komunitas sebagai tempat yang secara inklusif menyediakan layanan/ dukungan untuk anak yatim beserta keluarga dengan tujuan menyatukan mereka kembali.

Proses reunifikasi sendiri terdiri dari beberapa proses di dalamnya yaitu dimulai dari melengkapi permohonan reunifikasi, yang setelah itu dilakukan konseling dan penilaian terhadap anak. Selanjutnya ada konferensi kasus hingga pelacakan keluarga anak. Setelah ditemukan, maka diadakan pertemuan antara anak dan keluarga sekaligus pembinaan untuk perencanaan pengasuhan. Perencanaan ini melingkupi pembiayaan kehidupan anak dan bentuk pengasuhan ke depan. Terminasi atau pemutusan hubungan pelayanan dilakukan 
ketika reunifikasi telah teruji dan monitoring telah dilakukan (Utomo, 2017).

Untuk mencapai proses reunifikasi, beberapa aktivitas yang akan terlingkupi dalam fasilitas ini adalah, sebagai berikut: penelusuran dan penyatuan kembali keluarga, layanan akses kesehatan dan intervensi krisis, bimbingan dan konseling, penyediaan layanan untuk akses makanan bernutrisi dan tambahan pendidikan (workshop dan keterampilan).

Beberapa infrastruktur yang melingkupi aktivitas diatas adalah sebagai berikut: playground, counseling \& training center, kelas informal, ruang serbaguna, ruang administrasi dan dapur komunitas.

Aktivitas dan infrastruktur tersebut masih mengacu pada tujuan awal fungsi bangunan sebagai langkah deinstitusionalisasi (terutama pada poin ketiga) yaitu pengembalian anak pada keluarganya ataupun komunitas sebagai jenjang hidup lanjutan anak tersebut.

Selanjutnya realisasi ruang didesain sesuai dengan pendekatan psikologis. Hal ini penting karena pengguna kemungkinan besar juga mengalami masalah dalam hal psikologis. Ruang, gubahan, warna dan tekstur didefinisikan lewat teori reversal. Teori reversal adalah satu cabang ilmu/teori psikologi yang mengidentifikasi motivasi seseorang untuk menjelaskan pengalaman dan tindakan. Oleh karena itu pendekatan teori reversal diperlukan untuk mengarahkan motif pengguna didalam fasilitas ini, agar dapat mencapai tujuan reunifikasi dengan hasil yang lebih optimal.

Teori reversal terbagi menjadi empat bagian yaitu Means-end, rules, transaction, dan relationship. Masing-masing bagian terdiri dari dua status motivasi. Means-end dengan telic (serious) \& paratelic (playful), rules dengan conformist \& negavistic, transaction dengan autic \& alloic, relationship dengan mastery \& sympathy (Mullet et al., 2018).

Domain pertama yaitu means-end dengan dua statusnya yaitu telic dan paratelic akan digunakan untuk memperoleh pendekatan untuk konsep ruang yang akan digubah. Menurut Lewinski, 2015, dalam paratelic nantinya ruang akan bersifat lebih informal dan telic akan bersifat lebih formal. Sehingga dengan ruang paratelic, pengguna akan lebih menikmati dan menjadikan proses atau alur sebagai tujuan/motivasi. Sebaliknya dengan ruang telic, pengguna akan menjadikan akhir kegiatan menjadi tujuan.

Model Pengembangan ini diasumsikan untuk dikembangkan di kota Yogyakarta, yang tidak luput dari masalah yang sama terhadap anak yatim. Terdapat $26 \%$ penduduk Yogya merupakan anak-anak dan sejumlah 4.801 masih tinggal di panti asuhan (data tahun 2016) (BPPM, 2017). Data di atas menunjukkan bahwa masih banyak anak yang hidup dan tumbuh di panti asuhan. Pertimbangan lainnya adalah:

1. Isu perkotaan dan urbanisasi.

Kepadatan kota dan kecenderungan untuk hidup di kota yang terus meningkat memicu beberapa dampak negatif yang perlu diwaspadai yaitu sebagai berikut: menurunnya kualitas hidup lingkungan perkotaan, meningkatnya kriminalitas, dan terjadinya ketimpangan sosial yang lebih drastis.

2. Kondisi Perkampungan kota yang cenderung padat dan kumuh.

Kerentanan masyarakat yang ada didalamnya baik dari segi ekonomi dan pendidikan menjadi salah satu penyebabnya. Kondisi kepadatan yang cukup tinggi, menambah kemungkinan banyaknya komunitas dapat dijangkau oleh fasilitas yang ada di sekitarnya.

3. Kemudahan akses jalan dan transportasi.

Menurut Pak Jamruri (Kepala bagian Pendidikan Panti Asuhan Yatim Putra Muhammadiyah) lewat wawancara secara langsung, mayoritas anak-anak yatim ini berasal dari luar Daerah Istimewa Yogyakarta bahkan juga luar Pulau Jawa. Oleh karena itu, kemudahan akses akan sangat membantu dalam mempertemukan anak dan keluarganya untuk proses mediasi dan konseling.

\section{Deskripsi Tapak}

Lokasi tapak yang dipilih untuk pembangunan community center ini secara administratif terletak di J1. Kolonel Sugiono, Keparakan Lor, Mergangsan 1 RT.58/10 Yogyakarta. Luas tapak yang akan digunakan adalah sekitar 5000 $\mathrm{m}^{2}$ dengan keliling $412 \mathrm{~m}$. Lingkungan di sekitar tapak berupa wilayah pemukiman. 


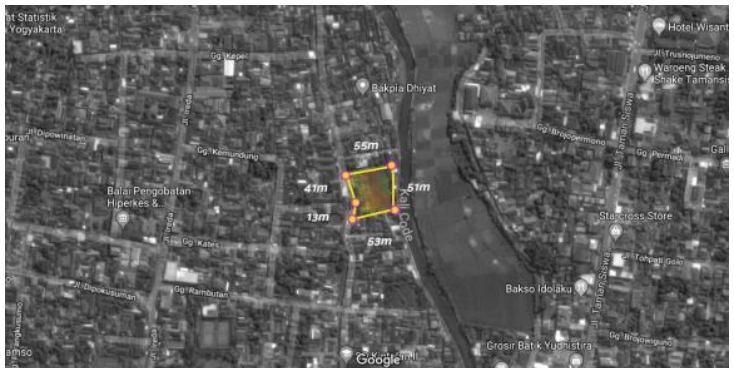

Gambar 2. Lokasi ta pak

Dilihat dari kacamata ekonomi, Kampung Keparakan terkenal sebagai sentra industri kulit. Sebagian besar penduduknya berprofesi sebagai pengusaha kerajinan kulit seperti sabuk, sandal, dan tas. Berawal dari tahun 1970, Industri ini lahir dan berkembang hingga sekarang. Bertahannya industri ini bukan tanpa alasan, kemudahan memperoleh bahan baku adalah salah satunya. Selain itu produk-produk di sini juga masih dibuat secara manual oleh pengrajin mulai dari tahap pembuatan pola, hingga tahap finishing sehingga membutuhkan banyak tenaga/pekerja. Maka dari itu, setiap pengrajin memiliki tenaga pembantu, entah dari keluarga maupun orang luar yang diberdayakan sebagai pekerja yang nantinya hasil produksi kerajinan ini dijual di pasar-pasar di Yogyakarta (Dwi \& Soeprapto, 2014).

Secara sosial, menurut Badan Pusat Statistik (BPS) Kecamatan Mergangsan, Kampung Keparakan terdiri dari 58 RT, 13 RW, dengan jumlah penduduk 9.923 jiwa. Warganya aktif dalam berbagai forum/organisasi seperti, RT (rukun tetangga), RW (rukun warga), karang taruna, forum anak. pembinaan kesejahteraan, forum pendidikan anak usia dini, kader kesehatan, paguyuban Kerajinan Indonesia (KERIND), Koperasi Kerajinan Keparakan Mandiri Sejahtera (KOKKMAS) (BPS, 2011).

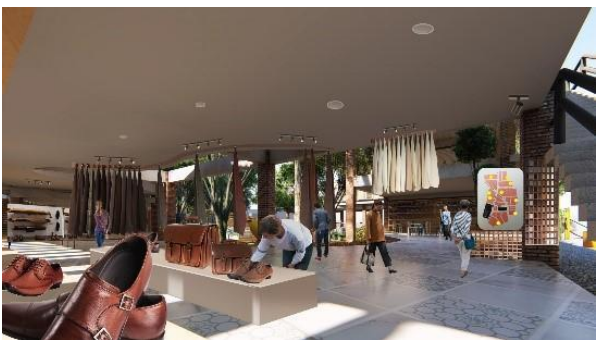

Gambar 3. Wa dah ekonomi komunitas

Kondisi eksisting pusat komunitas di kampung ini masih tersebar dan belum terintegrasi antara satu dengan yang lainnya. Banyaknya pusat aktivitas dan kegiatan masyarakat Kampung Keparakan perlu diwadahi dalam satu pusat kegiatan yang selanjutnya dapat dikembangkan untuk menjadi tempat reunifikasi anak yatim.

\section{Studi Kasus \\ a. Enabling Village (Fungsi-Lanskap)}

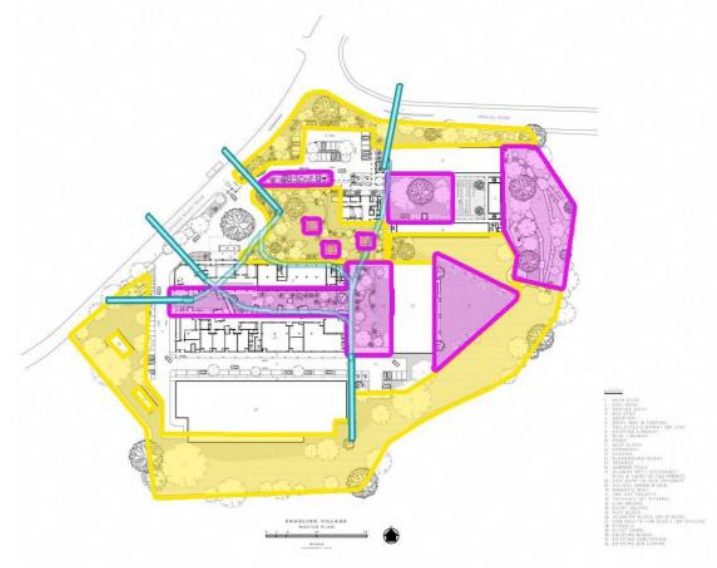

Gambar 4. Wa dah ekonomi komunitas

Enabling Village adalah bangunan bertipologi pusat komunitas yang terletak di Singapura dan secara inklusif juga memfasilitasi peran komunitas difabel. Dibangun dari pembaruan kembali bangunan lawas bekas Bukit Merah Vocational Institute yang berdiri pada tahun 1970an. Fasilitas ini mengintegrasikan pendidikan, vokasi, pelatihan, retail, serta menghubungkan orang difabel dengan masyarakat sekitar. Masterplan dari Enabling Village merepresentasikan sebuah taman yang menjadi koneksi jaringan pedestrian lingkungan sekitar.

Sifat ruangnya yang inklusif dan semi-terbuka membuat pengguna dan difabel di sini dapat berbaur dan mendapat peran dengan baik. Sehingga kedua pengguna ini terbiasa dan dapat beradaptasi satu sama lain dalam bersosial dan berinteraksi. Antar massa dan fasilitas di sini juga saling terintegrasi sehingga memudahkan akses pengguna untuk memanfaatkan berbagai fasilitas yang ada. 


\section{b. Bima microlibrary}

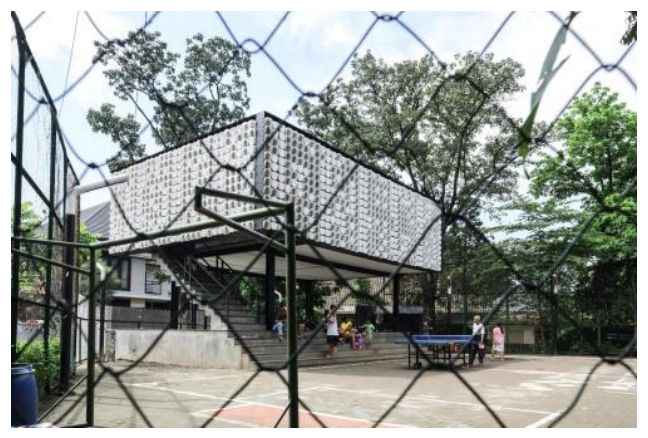

Gambar 5. Halaman depan yang Luas Sumber: archdaily.com (ArchDaily, 2016)

Bima microlibrary adalah satu ruang publik berupa perpustakaan kecil yang dibangun di lapangan sebuah komplek perumahan. Halaman yang cukup luas sangat diminati dan disukai warga sekitar yang hidup di tengah perkampungan padat ini. Fasilitas ini difungsikan sebagai ruang untuk menyelenggarakan berbagai acara, meleburkan semua rentang umur untuk beraktivitas bersama.

Lantai bawahnya difungsikan untuk acara kecil seperti pertemuan, rapat rutin ataupun diskusi ringan. Aktivitas informal lain seperti menonton film juga mewarnai ruang publik ini.

Sifat ruangnya yang terbuka membuat aktivitas disini dapat terkoneksi secara visual. Sedangkan ruang bawah yang bersifat fleksibel memberikan kesempatan pengguna untuk melakukan aktivitas sesuai dengan kebutuhan.

\section{c. One Village One Playground (Konteks Kampung-Teori)}

Sebuah proyek yang diinisiasi oleh PT. Urbane, berupa ruang komunitas di kampung Babakan Asih, Bandung. Kampung ini terkenal dengan julukan kampung preman karena banyak dari warganya yang sering melakukan tindak kriminalitas. Oleh karena itu, community space \& playground dibuat untuk memberikan perubahan signifikan pada pola pikir warga agar lebih kompak dan terbuka dengan sesama. Bentukan dari fasilitas ini cukup sederhana yaitu berupa satu massa bambu dengan lapangan di sampingnya. Ruang terbuka ini cukup untuk mewadahi berbagai aktivitas dan pergerakan warga di kampung ini.

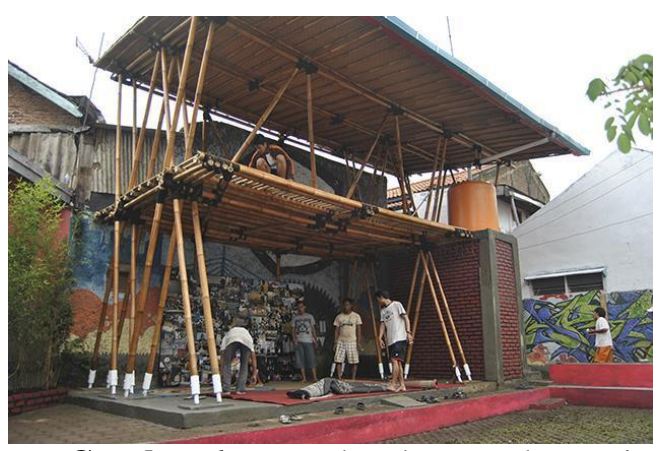

Gambar 6. Massa bambu pusat komunitas Sumber: urbane (Urbane, 2016)

Proyek ini juga membuktikan adanya kemungkinan keberhasilan untuk dilakukan di kampung-kampung atau pemukiman padat lainnya. Karena dilakukan secara swadaya, rasa kepemilikan yang tinggi juga membuat fasilitas ini lebih sustain, terdukung, dan terawat dengan baik.

Tabel 1. Komparasi kasus terhadap sifat ruang, bentuk ruang, Pengelola

\begin{tabular}{|l|c|c|c|}
\hline \multirow{2}{*}{ Kasus } & \multicolumn{3}{|c|}{ Ruang } \\
\cline { 2 - 4 } & Sifat & Order & Pengelola \\
\hline Enabling Village & $\begin{array}{c}\text { Semi- } \\
\text { publik }\end{array}$ & Tersebar & LSM \\
\hline $\begin{array}{l}\text { Bima } \\
\text { Microlibrary }\end{array}$ & publik & Terpusat & Komunitas \\
\hline $\begin{array}{l}\text { Village } \\
\text { Playground }\end{array}$ & publik & Terpusat & Komunitas \\
\hline
\end{tabular}

Tabel di atas membuktikan bahwa, keberhasilan pusat komunitas dalam mengaktifkan dan menghubungkan masyarakat setempatnya mempertimbangkan tiga aspek berupa sifat, order, dan sistem pengelolaan.

Komparasi kasus diatas memperlihatkan poin penting yang dapat diaplikasikan pada pusat komunitas di Kampung Keparakan, yang dalam hal ini adalah tempat reunifikasi anak yatim. Objek rancangan dapat memaksimalkan zona ruang yang bersifat publik agar interaksi antara anak dan warga kampung dapat berlangsung lebih intens. Pusat komunitas juga dapat dirancang dengan order menyebar agar mobilitas pengguna di dalam tapak lebih tinggi sehingga interaksi cair akan lebih sering terjadi di antara pengguna yang berpapasan secara tidak sengaja. Pengelolaan pusat komunitas mempengaruhi rasa kepemilikan tempat tersebut. Terkait dengan kemampuan 
masyarakat untuk mengelola, LSM diskemakan untuk ikut mendukung masyarakat dalam mengelola pusat komunitas kampung mereka.

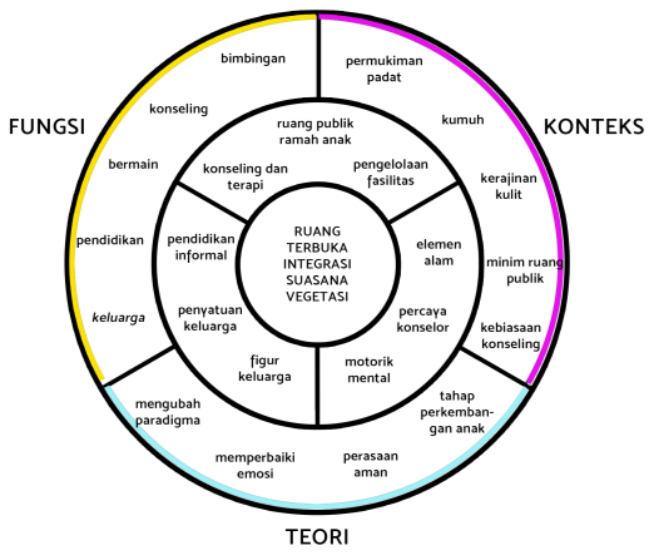

Gambar 7. Dia gram kata kuncimasalah

Dari analisis kata kunci permasalahan diatas, maka dirumuskan tiga masalah utama yang paling prioritas untuk dipecahkan dalam konsep dan perancangan. Berikut adalah ketiga permasalahan tersebut:

1. Bagaimana ruang terbuka kondusif ramah anak yang mempererat dan meningkatkan kualitas keluarga dan komunitas. Menciptakan halaman tengah yang bersifat fleksibel, fungsional, dan inklusif. Meningkatkan kualitas keluarga dan komunitas dengan berbagai macam aktivitas pengembangan diri.

2. Bagaimana menciptakan suasana ruang yang kondusif dan santai dalam aktivitas bimbingan dan konseling sehingga aktivitas ini menjadi lebih menarik dan dekat dengan masyarakat. Membiasakan kegiatan konseling agar menjadi keseharian yang positif bagi pengguna fasilitas di dalamnya.

3. Bagaimana alam mengintegrasikan ruang terbuka, fasilitas umum, dan rumah reunifikasi keluarga. Tentunya diperlukan integrasi yang baik serta fleksibilitas ruang agar setiap fungsi yang diprogramkan dapat tercapai dalam ruang yang optimal dan adanya kebutuhan untuk membuat satu ruang terbuka yang cukup lapang.

\section{Konsep: Therapeutic Courtyard}

Ditinjau dari rumusan masalah yang ada, pusat komunitas di perkampungan kota sebagai sarana pelayanan, edukasi, rekreasi komunitas, dan tempat reunifikasi anak yatim memerlukan satu konsep untuk dapat menyelesaikan permasalahan yang ada. Konsep yang dipilih sebagai solusi dari rumusan masalah yang ada adalah Therapeutic Courtyard. Konsep ini diimplementasikan lewat terciptanya halaman/ruang tengah yang mewadahi aktivitas bonding yang dapat meningkatkan ikatan antar pengguna, baik antar masyarakat, antara keluarga dan anak yatim, maupun anak dengan komunitas, yang secara tidak langsung dapat memperbaiki emosi/mental pengguna.

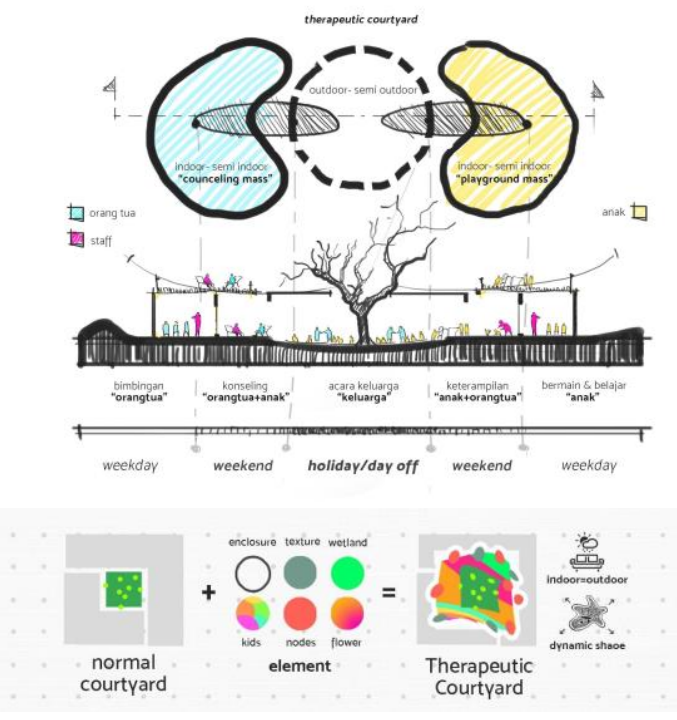

Gambar 8. Skema konsep courtyard

\section{a. Menciptakan "playground" yang Memicu Interaksi Orang Tua - Anak - Komunitas}

Dibentuk suatu wadah dan aktivitas yang bertujuan untuk meningkatkan ikatan/ kekompakan keluarga (orangtua dan anak) dan komunitas (anak dan masyarakat setempat). Maka dari itu, ruang yang tersedia harus dapat memicu adanya interaksi antar subjek-subjek tersebut. Yang dibutuhkan adalah ruang lapang yang bersifat fleksibel agar dapat mengakomodasi bermacam-macam acara dan berbagai aktivitas pengembangan diri anak sebagai bagian dari komunitas. Playground ini nantinya juga dapat menjadi wadah aktivitas anak dalam role playing (bermain satu peran tertentu). Role playing disini bertujuan untuk 
melatih kemampuan anak untuk bertanggung jawab dalam suatu kelompok, memahami dan menghargai kekurangan satu sama lain, serta menanamkan kebiasaan untuk dapat mengambil keputusan dalam bekerja dan bersosial (Prihandhana et al., 2015).

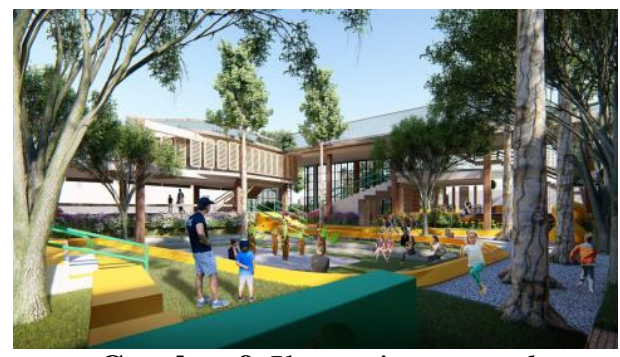

Gambar 9. Ilustrasi courtyard

\section{b. Ruang bimbingan dan konseling keluarga sebagai ruang yang melegakan}

Aktivitas bimbingan dan konseling memerlukan satu ruang yang lega dan tenang. Dekorasi dan luasan ruang yang dapat diatur dengan leluasa untuk mengatur suasana hati dalam berbagai mode aktivitas sangatlah dibutuhkan. Kegiatan dan tempat ini nantinya juga akan berperan sebagai rumah kedua bagi anak yang sudah tidak memiliki keluarga untuk mencari sosok yang dapat dianggap dan berperan sebagai orang tua.

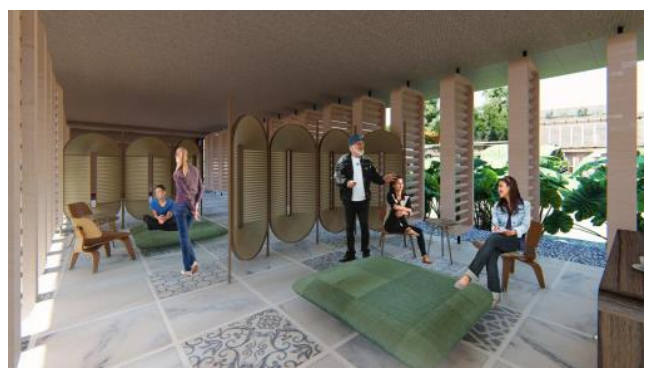

Gambar 10. Ilustrasi ruang konseling

\section{c. Elemen alam sebagai batas dan pelebur ruang yang menciptakan efek terapeutik}

Elemen alam dan vegetasi berperan sebagai batasan dan menjadi bagian dari atmosfer ruang. Hal ini bertujuan untuk membatasi dua aktivitas yang berbeda sekaligus memberikan efek terapi pada pengguna yang ada di dalam fasilitas. Di sisi yang lain, beberapa ruang dileburkan agar mendapatkan kesan ruang yang lebih terbuka dan mempermudah pengawasan. Dengan demikian, koneksi visual dapat terjadi dan orang-orang lebih sering untuk saling bertemu. Hal ini memunculkan adanya kebersamaan untuk menciptakan sebuah toleransi, mengenal dan menerima satu sama lain. Toleransi berperan dalam proses penyesuaian adab atau tingkah laku keseharian dengan norma-norma dalam kebiasaan yang dianut oleh masyarakat sekitar hingga tercapai kesepahaman dan keselarasan tingkah laku (Prasetya et al., 2015).
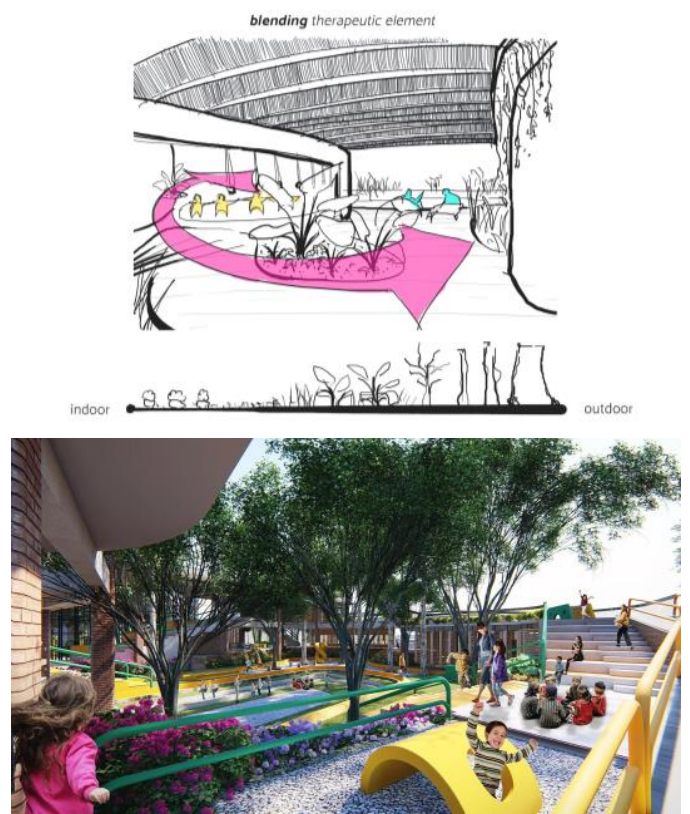

Gambar 11. Ala m sebagai pembatas dan atmosfer

Ketiga solusi dari konsep therapeutic courtyard di atas digabungkan menjadi satu. Solusi ini juga digunakan sebagai acuan penggubahan massa, denah, tampak dan potongan bangunan secara keseluruhan.

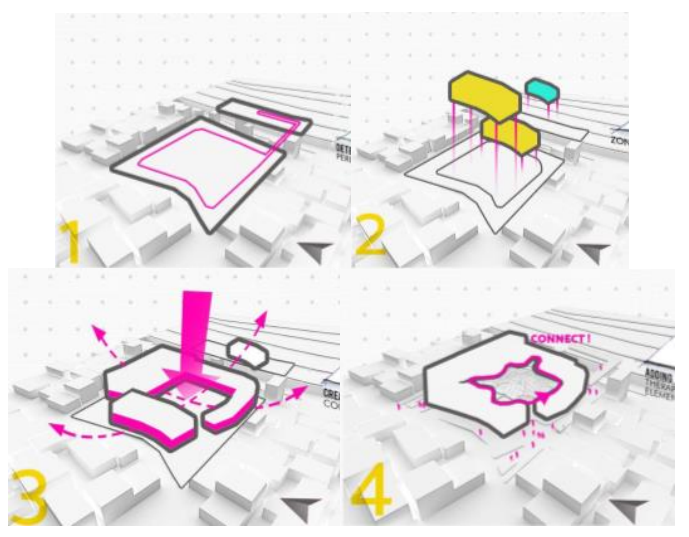

Gambar 12. Transformasi gubahan massa 


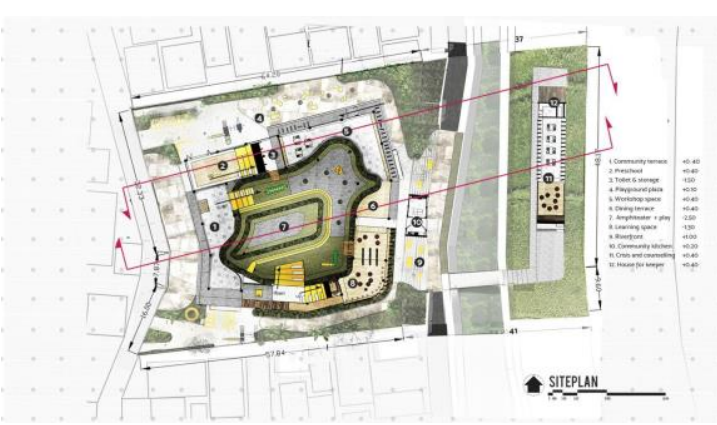

Gambar 13. Rencana Tapak Pusat Komunitas

Massa pada pusat komunitas bersambung dan berorientasi ke tengah therapeutic courtyard membentuk ruang yang lapang secara visual dan fleksibel untuk digunakan dalam kebutuhan yang bermacam.

\section{KESIMPULAN}

Artikel ini bertujuan memaparkan perancangan arsitektur fasilitas yang mengakomodasi kebutuhan kegiatan deinstitusionalisasi anak berupa reunifikasi keluarga (sebagai antitesis dari kegiatan institusionalisasi dalam panti asuhan). Perancangan ini merumuskan bahwa permasalahan utama yang perlu diselesaikan adalah terkait penciptaan ruang-ruang yang mendukung reunifikasi keluarga, yaitu pada desain ruang terbuka, ruang konseling dan cara mengintegrasikan dengan fasilitas-fasilitas lain.

Konsep therapeutic courtyard digagas sebagai solusi masalah tersebut di atas. Konsep ini dapat menjadi model acuan yang diterjemahkan dalam strategi transformasi desain (1) kegiatan/program playground sebagai pemicu interaksi orang tua-anak-komunitas, (2) ruang bimbingan konseling keluarga yang melegakan, dan (3) elemen alam sebagai batas dan pelebur ruang yang menciptakan efek terapeutik. Ketiga strategi tersebut dapat diterapkan pada pusat komunitas maupun fasilitas reunifikasi yang telah ada, serta dapat dikembangkan dan diuji lebih lanjut agar menemukan formula yang lebih tepat guna.

Gagasan dalam rancangan ini merupakan rancangan hipotesis yang belum terbangun, namun telah melewati ujian tugas akhir S1 Arsitektur Fakultas Teknik Universitas Gadjah Mada dan coaching desain penjurian Asian Young Designer Awards 2017/2018.

\section{UCAPAN TERIMAKASIH}

Ungkapan terimakasih ditujukan kepada lembaga Panti Asuhan Yatim Putra Muhammadiyah Lowanu Yogyakarta yang telah membantu peneliti dalam proses pendalaman masalah panti asuhan. Terimakasih juga ditujukan pada pengelola Program Studi S1 Arsitektur Fakultas Teknik Universitas Gadjah Mada atas dukungan terhadap keikutsertaan desain ini dalam kompetisi AYDA 2017/2018 hingga mendapatkan penghargaan Bronze Award (juara ketiga).

\section{REFERENSI}

Apsari, N. C., \& Nurwati, R. N. (2017). Keadaan Pemenuhan Hak Pendidikan Anak Remaja Pasca Reunifikasi. Share: Social Work Journal, 7(2), 1-79. https://doi.org/10.24198/share.v7i2.1568 7

ArchDaily. (2016). Bima Micro Library / SHAU Bandung. Www.Archdaily.Com. https://www.archdaily.com/790591/bim a-microlibrary-shau-bandung

BPPM. (2017). Data Gender dan Anak D.I. Yogyakarta. BPPM DIY.

BPS. (2011). Statistik Daerah Kecamatan Mergangsan 2016 (S. Z. Purwoko (ed.)). BPS Kota Yogyakarta.

Child Welfare Information Gateway. (2017). Guiding Principles of Systems of Care: Community-Based Services. Www.Childwelfare.Gov.

https://www.childwelfare.gov/topics/ma nagement/reform/soc/history/communit $\mathrm{y} /$

Dwi, F., \& Soeprapto. (2014). Dinamika Pengembangan Usaha Koperasi: Studi pada Koperasi Kerajinan Keparakan Mandiri Sejahtera/ KOKKMAS di Kampung Kerajinan Keparakan Kidul, Yogyakarta. Skripsi Mahasiswa Sosiologi Universitas Gadjah Mada, 28.

Eurochild. (2014). De-institutionalisation and Quality Alternative Care for Children in Europe: Lessons Learned and The Way Forward (Issue March). https://www.openingdoors.eu/wpcontent/uploads/2014/11/DI_Lessons_L earned_web_use.pdf

Graham, T. (2017). Lion Cub in Search of his Original Pride: Reflections on Saroo 
Brierley's Adoption Story. Ipsify.Com. https://www.ipsify.com/lion-cub-insearch-of-his-original-pride/

KBBI. (2016a).

Komunitas.

Kbbi.Kemdikbud.Go.Id.

https://kbbi.kemdikbud.go.id/entri/komu nitas

KBBI. (2016b). Panti Asuhan. Kbbi.Kemdikbud.Go.Id.

https://kbbi.kemdikbud.go.id/entri/panti asuhan

KBBI. (2016c). Pusat. Kbbi.Kemdikbud.Go.Id. https://kbbi.kemdikbud.go.id/entri/pusat

Lumos. (2014). Ending the Institutionalisation of Children Globally - the Time is Now. https://www.wearelumos.org/resources/t ime-now-ending-institutionalisationchildren-globally/

Moyo, S., Susa, R., \& Gudyanga, E. (2015). Impact of Institutionalisation of Orphaned Children on Their Wellbeing. IOSR Journal Of Humanities And Social Science Ver. III, 20(6), 63-69. https://doi.org/10.9790/0837-20636369

Mullet, E., Kpanake, L., Zounon, O., Guedj, M., Mullet, E., Kpanake, L., Zounon, O., Guedj, M., Muñoz, M., Putting, S., Zounon, O., Guedj, M., Teresa, M., \& Sastre, M. (2018). Putting Reversal Theory ' $s$ Model of Four Domains of Experience in the Hot Seat. HAL, 2, 10.

Prasetya, A. B., Purnomo, M. D. E., \& Widodo, A. S. (2015). LEMBAGA PEMASYARAKATAN ANAK DAERAH ISTIMEWA YOGYAKARTA SEBAGAI WADAH PEMBINAAN KEBERSAMAAN UNTUK MENUMBUHKAN TOLERANSI MENGGUNAKAN PENDEKATAN PERILAKU DALAM ARSITEKTUR. Arsitektura, 13(1), 10.

Prihandhana, B., Musyawaroh, \& Daryanto, T. J. (2015). WAHANA EDUKASI PROFESI ANAK DI SURAKARTA DENGAN ARSITEKTUR PENDEKATAN PERILAKU. Arsitektura, 13(2), 7.

Urbane. (2016). One Village One Playground Babakan Asih. Www.Urbane.Co.Id. http://www.urbane.co.id/ovop/

Utomo, S. (2017). PROSES REUNIFIKASI ANAK ASUH (STUDI KASUS PADA PANTI SOSIAL ASUHAN ANAK ( PSAA
) UNIT BIMOMARTANI, SLEMAN, YOGYAKARTA). 39.

van IJzendoorn, M. H., Luijk, M., \& Juffer, F. (2008). IQ of Children Growing Up in Children's Homes: A Meta-Analysis on IQ Delays in Orphanages. Merril-Palmer Quarterly, 54, 27.

Wicahyo, G. S. (2018). PENGEMBANGAN MEDIA PEMBELAJARAN BERBASIS PERMAINAN MONOPOLI PADA MATERI PERENCANAAN PEMASARAN KELAS X JURUSAN PEMASARAN SMK KETINTANG SURABAYA. Jurnal Pendidikan Tata Niaga (JPTN), 1(2), 5. 